\title{
TENTATIVA DE INTEGRAÇÃO ENTRE ALGUMAS CONCEPÇÕES BÁSICAS DA PSICANÁLISE E DA NEUROCIÊNCIA
}

\author{
Yusaku Soussumi*
}

\section{RESUMO}

O autor aborda a falta de uma visão integrativa do ser humano que existe no estudo da neurociência e da psicanálise, em face da educação e da cultura fundamentadas sobre o paradigma da fragmentação. Essa visão fragmentada leva os estudiosos a desconsiderar a unidade sobre a qual se desdobraram os fatos e os fenômenos subseqüentes no processo de desenvolvimento e evolução dos seres vivos. $\mathrm{O}$ autor toma o instinto de sobrevivência, que é inerente à própria vida e a todo ser vivo, como a unidade que está na base de todos os fenômenos orgânicos e mentais e tenta estudar suas expressões, integrando fenômenos neurobiológicos e psicológicos, que são indissociáveis, de acordo com a visão de autoregulação concebida por Freud.

Palavras-chaves: psicanálise, neurociência, afeto, emoção, sentimento, instinto de sobrevivência

\section{Abstract}

ESSAY ON INTEGRATION OF SOME BASIC PSYCHOANALYTIC CONCEPTS WITH BASIC CONCEPTS OF NEUROSCIENCE

The author has reported his own apprehensions about the lack of integrative vision in the study of neurosciences and psychoanalysis, related to the fact that our education and culture are based on the paradigm of fragmentation. The consequence of this fragmented vision is that the specialist can not capture the unity of the facts and the subsequent phenomena within the

* Membro Efetivo da Sociedade Brasileira de Psicanálise de São Paulo, Membro Fundador da Sociedade Internacional de Neuropsicanálise, Presidente do Centro de Estudos e Investigação em Neuropsicanálise. 
process of development and evolution. The author has taken the survival instinct that is inherent to life itself and to all live beings as a basis that is common to all organic and mental phenomena and tries to study their expressions, integrating neurobiological and psychological phenomena, which are inseparable, within the vision of self-regulation conceived by Freud.

Keywords: psychoanalysis, neuroscience, affect, emotion, feeling, survival instinct

Nas minhas incursões no campo da transdisciplinaridade e do saber da complexidade, pude conhecer extraordinários pensadores que analisam criticamente a condição atual do saber geral e do saber científico, em particular. Além da sobejamente conhecida questão do conhecimento fragmentado, em que se perde a visão do todo, questão essa que a quase totalidade da civilização carrega em função do currículo das escolas desde o ensino elementar até o acadêmico, outras questôes relacionadas ou conseqüentes a essa estão presentes nas disciplinas científicas. Vi confirmar-se o que observava desde meus anos de formação, tanto no campo da medicina quanto da psicologia: os colegas, além de não terem, em geral, uma visão integrada do homem, também careciam de uma visão compreensiva do ímpeto subjacente que deu e dá significado ao fenômeno da vida e à luta pela sua manutenção, que acaba por se confundir com a própria vida, está presente e rege todos os passos da manifestação de um organismo, seu comportamento e suas atividades.

Creio que faltou, no processo educacional de formação do homem do saber, e da ciência de forma geral, essa ênfase no fenômeno da vida, englobando as condições que a fizeram surgir. As peculiaridades desse fenômeno, do ponto de vista da energia, contrariam a segunda lei da termodinâmica, e, como conseqüência, há uma luta perene para que essa vida se mantenha, a ponto de a vida, suas peculiaridades, suas modalidades e criações se expressarem como manifestaçôes diretamente relacionadas à problemática da sobrevivência e da sua manutenção.

Isso talvez tenha acontecido pela dificuldade de compreender a intimidade complexa do fenômeno, campo em que alguns físicos de vanguarda, como Schrodinger, tentaram desvendar algumas motivações e propuseram desafios à curiosidade. Mas, a não ser no campo específico do estudo da biologia sob o prisma da complexidade, as ciências biológicas, em especial as médicas e psicológicas, preferem ver o ser humano como uma máquina acabada e, em suas consideraçôes, não cogitam que as manifestaçôes humanas, sejam orgânicas, sejam psicológicas, nascem e estão presentes em função de questóes ligadas ao instinto de sobrevivência, que está em jogo em todo e a cada momento da vida. 
Assim, podemos compreender que, na concepção do tempo numa dimensão que transcende o psicológico da terceira dimensão, estamos na vigência plena do organismo recém-surgido para o fenômeno da vida, procedendo a experimentações com base em ensaio e erro para encontrar os mecanismos mais eficazes asseguradores de sua manutenção e sobrevivência, ao mesmo tempo que busca garantir uma auto-organização, uma autocriação em direção ao aperfeiçoamento contínuo do seu próprio sistema.

Podemos compreender a evolução, o desenvolvimento, a auto-regulação e a homeostase como movimentos que integram um conjunto maior de movimentos do organismo voltados para a economia da vida, os quais particularizamos quase sempre perdendo de vista a razão de ser que os mobiliza.

Ficaremos surpresos, talvez, ao nos darmos conta de que a tão decantada e preciosa racionalidade de que tanto se orgulha a civilização ocidental, a ponto de propor uma dicotomia para expurgar o obscurantismo do corpo e das emoções, na realidade é mera expressão dos mecanismos de sobrevivência que a natureza buscou como recurso na sua experimentação. É assombroso que as grandes conquistas do homem, resultado de mentes privilegiadas como as de Einstein, Bohr, Heisenberg, Freud, Lacan, etc, nada mais sejam do que expressões da conquista de recursos para uma sobrevivência humana melhor.

Somos todos seres vivos em busca de caminhos mais adequados e de recursos mais eficazes, pelo método do ensaio e erro, para assegurar a vida e espalhá-la pelo cosmos. Talvez a compreensão de que cada um de nós se encontra engajado nessa luta particular, que é igual para todos, possibilite que os homens possam ver-se com mais humildade e empatia um com o outro. Creio também que essa visão vai permitir compreender porque alguns, no afã de assegurar a própria sobrevivência, cegamente, pelo método do ensaio e erro, destruam o seu habitat e mostrem-se surdos às tentativas daqueles que querem mostrar-lhes o que fazem: o impulso de sobrevivência não os deixa ver nem ouvir nada que não seja consentâneo com sua razão.

Por outro lado, esses mesmos fatos permitem entender por que teorias como as de Humberto Maturana e Francisco Varela encontraram uma repercussão restrita nos meios acadêmicos, tendo mesmo sofrido sutil rejeição. No meu ponto de vista, as teorias de Maturana e Varela se baseiam exatamente na concepção do homem tomado como qualquer ser vivo, envolvido, portanto, no processo de manter a vida e de buscar aperfeiçoar os recursos de sobrevivência. Em função de suas formações básicas, os investigadores não encontram, nas teorias de Maturana e Varela, ressonância para seus paradigmas de pensamento, estes mesmos conduzidos por automatismos, em busca do que é familiar e reconhecível. Teorias como 
as de Maturana e Varela tornam-se, por isso, enfadonhas, pouco atraentes e ininteligíveis.

Em junho de 2000, a Academia de Ciências de Nova York patrocinou uma conferência intitulada "A Unidade do Conhecimento: a Convergência da Ciência Natural e Social", que congregou eminentes cientistas das áreas da biologia, da neurociência, da psicologia, da psicologia social, da sociologia e da antropologia, para identificar um tema consensual, unificador das diferentes e complexas manifestações de cada ciência. $\mathrm{O}$ resultado pode ser avaliado com uma frase conhecida de Einstein, "Nós podemos construir as coisas o mais simples possível, mas não o mais simples", referida por Moss e Damásio no seu artigo "Emotion, cognition and the human brain" (2001: 98).

No entanto, muitos, como eu, saíram da conferência com o tema o mais simples possível que conhecemos como tema orientador básico no qual se pudessem ancorar os desdobramentos e as situações que emergiram em cada momento histórico, cada vez mais complexos, e objeto de estudo de diferentes disciplinas no nosso caso, a neurociência e a psicanálise -, de uma forma que permitisse um conhecimento integrado da totalidade a partir de uma linha evolutiva de abordagem e compreensão. Sentimo-nos fortalecidos na nossa postura, porque já vínhamos utilizando essa forma de abordagem para embasar e justificar nossas idéias.

Nesse exercício de encontrar um ponto comum de convergência, de consiliência, conforme considera Edward Osborne Wilson (1998), entre ciências naturais e ciências humanas, Henry Moss e Antonio Damásio dizem no artigo "Emotion, cognition and the human brain":

Assim como a distinção entre nature-nurture se encontra em declínio em termos de utilidade, assim também acontece com a dicotomia mente-corpo ou mente-cérebro. Quanto mais acuradamente olhamos para as funçôes cognitivas - percepção, sentimento, memória, linguagem, razão - mais reconhecemos o envolvimento do corpo. Para um organismo capaz de achar seu caminho no mundo, as funções biorregulatórias são urdidas por corpo e mente juntos. Antonio Damásio assinala a negligência da emoção no século XX pela ciência cognitiva e pela neurociência cognitiva e sugere que sem considerar a emoção nós não podemos colocar a mente em relação às suas origens evolutivas, nem aos seus papéis no organismo como um todo. Sem a emoção nós não podemos compreender como o organismo mantém a homeostase em face dos desafios do meio ambiente e ameaças à sobrevivência no mundo complexo da sociedade e cultura. As emoções e os sentimentos que seguem as emoçôes são parte integrante dos sistemas de valores necessários para estabelecer a memória de longo 
prazo e para racionalização e tomada de decisão envolvendo as escolhas para direcionar a vida (Damásio, 2001: 98).

Se, para a neurociência, houve negligência na consideração das emoções e, em conseqüência, da sobrevivência como fator fundamental na determinação das funçôes homeostáticas e das formas de viver, a psicanálise, de seu lado, lidou com as emoçôes sem considerar sua inserção no corpo, que ela negava, e muito menos a questão da sobrevivência, porque esta diz respeito ao corpo. Ou seja, as emoções eram consideradas em si e não como expressões ligadas à sobrevivência, decorrentes dos estados do meio interno ou corporal. Dessa maneira, ignorava-se que as funções psíquicas fossem recursos utilizados pelo organismo na sua auto-regulação, no seu processo de garantir a sobrevivência. Assim sendo, o desenvolvimento e a evolução não eram pensados em termos de aperfeiçoamento dos recursos utilizados pelo organismo para alcançar respostas mais adequadas aos desafios do meio e mais ampla adaptação.

Penso que a junção entre neurociência e psicanálise permite a integração mente-corpo como um todo inseparável, em que é possível constatar a existência de um encadeamento contínuo entre manifestações corporais e psíquicas, de forma indissociável. Mas estejamos atentos porque nem todas as neurociências vão permitir essa seriação contínua, pois, como observamos no exemplo citado no início deste artigo e como Damásio assinala em seu artigo "Emotion and the human brain",

[...] a prevalente ausência da noção de organismo na ciência da mente e do cérebro. Não se refere só ao fato de que a mente esteve ligada ao cérebro numa relação equivocada, mas que o cérebro permaneceu consistentemente separado do corpo e assim não fazendo parte da profunda tessitura - corpo e cérebro, que define o organismo complexo. Novamente, a noção de organismo esteve disponível mas pouco usada (Damásio, 2001:102).

Além dessa negligência, também a noção de homeostase foi desprezada nas ciências por neurocientistas e psicólogos. Isso não significa que não houvesse inúmeros cientistas preocupados em compreender a neurofisiologia da homeostase, a neuroquímica do sistema nervoso autônomo, os mecanismos da regulação endócrina ou a inter-relação entre o sistema nervoso, o sistema endócrino e o sistema imunológico. Refiro-me ao fato de que as conquistas nessas áreas não foram levadas em conta na compreensão do funcionamento do cérebro e da mente.

Tendo estabelecido esses aspectos, ficou claro para mim que, se eu desejava fazer um trabalho que resultasse em contribuição efetiva a neurocientistas e psica- 
nalistas, eu teria de buscar, no nível do possível, uma integração que me permitisse penetrar nos meandros do dinamismo dos fenômenos neurobiológicos, que a neuropsicologia permite, e nos meandros do dinamismo psíquico, que é o domínio da psicanálise. Arriscaria que, desse mergulho, resultasse uma hibridização de concepções e conceitos, sem perder a identidade psicanalítica, o grande temor dos psicanalistas. Não daria para permanecer no nível da simples enunciação de correlações à distância, numa atitude de simples aproximação interdisciplinar que não supóe o risco de um envolvimento maior, de um mergulho nas duas disciplinas, mas garante a preservação clara, fóbica, dos limites. O desenvolvimento do estudo das relações entre neurociência e psicanálise, do qual a neuropsicanálise constitui uma modalidade, já requer muito mais daqueles que nele estão efetivamente envolvidos e adotam essa postura.

Pela minha leitura, Freud traz, em toda a sua obra, os estudos de suas observações sobre as vicissitudes do homem submetido aos imperativos do instinto de sobrevivência e sua busca de condições mais elevadas de regulação. Além de seu extraordinário conhecimento das humanidades, Freud serve-se também do profundo conhecimento e do domínio que possuía no campo da biologia e da neurologia, o que foi e é negligenciado pelo establishment psicanalítico. Podemos dizer que, em face dos paradigmas racionalistas derivados da dicotomia cartesiana mentecorpo, os psicanalistas têm-se mostrado cegos à riqueza de evidências biológicas presentes nos escritos de Freud.

Desde o Projeto para uma psicologia cientifica (1895), Freud enuncia que o aparelho mental existe para fazer face a necessidades internas do ser decorrentes do imperativo de sobrevivência, num meio externo em constante mudança. A partir dessa concepção, podemos, de forma bem esquemática neste trabalho, apresentar os aspectos concomitantes, como dizia Freud, neurocientíficos e psicanalíticos, do desenvolvimento do mecanismo de auto-regulação biopsíquica no homem.

A regulação do organismo se dá pelo controle das condições do meio interno, ou seja, para que a vida exista, é necessário que o meio interno esteja dentro de determinados parâmetros. Por essa razão, o organismo tem um rigoroso controle sobre as condiçôes do meio interno. As variações desse meio são captadas por sensores, estruturas presentes desde as primeiras células. No homem, as variações do meio interno são captadas como afetos e se manifestam numa dualidade de estados: de desprazer, quando alterado, e de ausência de desprazer, ou prazer, quando equilibrado, harmônico. Essa dualidade de estados se define pela oposição e o que se convencionou chamar de princípio do prazer constitui o valor determinante da mobilização do organismo na busca das condiçóes necessárias e suficientes para a 
sobrevivência, pela mudança da condição que provoca o estado de desprazer para a condição que provoca o estado de prazer.

Freud assinalou que os afetos são percepções dos estados internos do organismo, que se distinguem das percepções do mundo externo, na sua obra Interpretação dos sonhos (1900), quando afirma que podemos ver a consciência como um órgão sensorial para a apreensão de qualidades psíquicas, que recebe excitações de duas fontes: a primeira, da periferia, vindo de todo o aparelho mental que ele chama de sistema perceptual (Pcpt), e, a segunda, de excitações sob a forma de prazer e desprazer, que são qualidades ligadas a transposições de quantidades de energia no interior do aparelho mental.

Uma vez referido que Freud concebia os afetos nitidamente a partir de um esquema neurobiológico que ele tinha em mente, é interessante buscar na neurociência os correlatos dessa idéia. Parece que existe um consenso entre os mais eminentes neurocientistas dedicados ao estudo dos afetos e das emoçõos, como Damásio (2001), LeDoux (1998), Panksepp (1996), Watts (2003), entre outros, de que as emoções são percepções de processos internos, que ocorrem no nível do consciente, em sítios diferentes e dissociados daqueles ligados às modalidades sensoriais mais conhecidas, relacionadas com a apreensão do mundo externo, como a visão, a audição, o paladar, o olfato e o tato.

Sabemos que a percepção consciente do mundo exterior, que é capturada pelos órgãos sensoriais situados no corpo do indivíduo, é projetada no córtex cerebral unimodal primário e secundário, tornando-se, assim, uma atividade cortical. Por outro lado, a experiência afetiva se correlaciona com a atividade no sistema límbico, como, por exemplo, o complexo amigdalóide para as situações de desprazer, a substância inominata e a área septal, que constituem o núcleo basal do cérebro anterior, para as situaçōes de prazer, e com outros núcleos da base do cérebro, como o hipotálamo, o accumbens, o estriado, o PAG, etc. Além de áreas paralímbicas, como o cingulado anterior, a área ventromedial do pré-frontal para as situaçôes emocionais mais complexas, parecendo constituir as estruturas de captura dos estímulos sensoriais derivados dos estados do corpo.

Mais recentemente, Antonio Damásio (2004) e outros autores trouxeram suas hipóteses sobre os mapas corporais nas regiões corticais somatossensoriais, nas quais os estímulos sensoriais seriam projetados, depois de identificados nas regiôes límbicas e paralímbicas, e constituiriam as configurações dos estados corporais a cada momento sob a forma de mapas neurais. Esses mapas neurais, por sua vez, seriam transformados em consciência de experiências afetivo-emocionais, tornando-se sentimentos. Sabe-se que o sistema nervoso, principalmente o cérebro, é capaz de mapear as estruturas do corpo e os seus múltiplos estados nas suas 
modificações constantes, além de ser capaz de transformar os padrões neurais desses mapas em padrōes mentais, como, por exemplo, em imagens e pensamentos. Assim sendo, nossas emoções e sentimentos se baseiam, na sua essência, nesses padrões de atividades das regiōes cerebrais somatossensoriais. Se essas regiōes não estivessem disponíveis, não seríamos capazes de sentir, da mesma forma que não seríamos capazes de ver coisa alguma, se estivéssemos privados das regiôes visuais do cérebro. Dito de outra forma, o tecido cerebral tem a capacidade de transformar os padrões neurais em pensamentos, imagens e vivências emocionais, haja vista que, sem isso, as atividades neurais na área unimodal secundária para a visão não produziriam as imagens. Da mesma forma, essa atividade neural que corresponde a mapas de estados corporais nas regiōes somatossensoriais seria transformada em vivências emocionais e sentimentais. Esses mapas corporais ocorreriam nas regiōes da ínsula, SI e SII, regiōes cerebrais que se conectam com áreas préfrontais, principalmente o orbitofrontal, o dorsolateral do pré-frontal e o cingulado anterior na área paralímbica.

A existência dos mapas corporais cujas atividades são responsáveis pela consciência das emoções, à semelhança das áreas corticais sensoriais secundárias, trouxe uma compreensão mais profunda sobre os afetos como uma modalidade de percepção de natureza diferente das percepções do mundo externo, que também têm um componente que se projeta nas estruturas corticais, a partir das quais alcançam a consciência e se transformam em sentimentos.

Uma das grandes questôes sobre as quais Freud se debruçou, da mesma forma que estudiosos de hoje, é a questão inevitável de ter de considerar como os estados do meio interno, que se expressam por quantas de energia, em termos de processos quantitativos, podem ser captados em termos qualitativos, como afetos de desprazer e prazer.

Podemos dizer que, nos seres vivos mais primitivos e no homem, nas condições mais primitivas logo após o nascimento, esses estados correspondem a condiçôes mais fisiológicas, ou seja, corporais, porque as estruturas cerebrais envolvidas são as regiôes subcorticais representadas pelos núcleos do tronco cerebral, núcleos da base do cérebro anterior e do sistema límbico, nos quais predomina um tipo de resposta binária, de pouca discriminação, discriminação essa que só pode ser alcançada pela atividade cortical. Nessas áreas também domina a atividade automática, involuntária, pré-programada, inata e inconsciente. A atividade consciente, voluntária, controlada, só vai ser alcançada na área cortical. É dessas regiōes subcorticais, segundo Freud, que derivam os impulsos motivacionais que levam os organismos a buscar desfazer-se do acúmulo de energia, sentido como desprazer, para uma condição de baixa energia, sentida como estado de prazer. A dimensão 
quantitativa, portanto, corresponde a uma atividade global do organismo, inespecífica, que demanda de uma mente primitiva, uma proto-mente, tão-só a capacidade de percepção e trabalho em termos de prazer e desprazer, de forma reflexa, automática, estereotipada e pré-programada, em função de promover a sobrevivência. Esse impulso, presente já nesse momento primitivo, que vai provocar e estimular modificaçóes nas respostas no decorrer do processo de desenvolvimento do homem, Freud chamou de Trieb e foi traduzido em inglês por drive, e nós poderíamos chamar de impulsos motivacionais ou impulsos instintivos, ou, como vem sendo consagrado no meio psicanalítico de língua portuguesa, de pulsão. Para Freud, drive seria: "o representante psíquico do estímulo originado dentro do organismo e que alcança a mente, como uma demanda por trabalho sobre a mente em conseqüência de sua conexão com o corpo" (Freud, 1915: 123).

Nos primeiros momentos de vida, o homem responde às solicitações de sobrevivência por meio de respostas restritas ao desprazer e ao prazer, ou seja, dentro do princípio do prazer, numa modalidade de funcionamento denominada processo primário, sob o controle de uma instância que Freud chamou de ego. Tratase de uma instância ligada à percepção dos afetos e que funciona de forma préprogramada, estereotipada, automática, cuja função é promover a restauração do equilíbrio do meio interno. Como já considerava Freud no Projeto para uma psicologia científica (1895), o organismo traz, de forma inata, como herança filogenética, uma instância primitiva que ele chamou de id (que corresponde aos domínios da região subcortical acima assinalada) e que guarda disposições pré-programadas, que levam a buscar a sobrevivência na sua relação com o meio externo e com o qual se relaciona sob a forma de impulsos instintuais para satisfazer suas necessidades. Há, pois, um impulso que nasce dentro do organismo, invade a instância chamada ego e vai ao encontro dos objetos necessários situados no meio externo, percebidos por esse mesmo ego. Desse encontro resulta a experiência de satisfação, ou frustração, que vai ser inscrita como traço de memória e vai constituir o parâmetro para as experiências subseqüentes. Os impulsos motivacionais que levam à busca da satisfação das necessidades e que nascem dos estados corporais se encontram com os elementos do mundo externo que, dentro da programação, correspondem aos objetos de satisfação das necessidades e são percebidos pelas percepções sensoriais fruto dos estímulos advindos do mundo externo.

Os impulsos, ou afetos, carregados de energia acumulada e, portanto, provocando a experiência de desprazer, se encontram no ego com as representaçóes do mundo externo que contêm o objeto buscado, e, nesse momento, com base no princípio do prazer, ocorre a descarga de energia que restabelece o equilíbrio e elimina o estado de desprazer. 
A neuropsicanálise identificou nas funçōes do lobo frontal muitas das funções atribuídas ao ego. Sabemos, pela neurobiologia, que o lobo frontal é a parte mais desenvolvida do cérebro, em especial o pré-frontal, que encontra no homem a sua expressão mais evoluída, a ponto de constituir quase que exclusivamente os $2 \%$ que o distinguem geneticamente do chipanzé, o primata mais próximo do homem. Dotado de função associativa, o lobo frontal recebe os estímulos de todas as demais estruturas do cérebro e os associa, integrando-os. De forma esquemática, os estímulos relativos aos estados de cada parte do corpo chegam ao cérebro pela medula espinhal, por meio do tronco cerebral, por vias aferentes, onde vão estimular os diversos núcleos que aí se encontram. Essa é a estrutura mais antiga do cérebro, que compartilhamos com os animais inferiores, e, mesmo em momentos precoces de nossas vidas, está funcionando e controla nosso corpo. Além da PAG (substância cinzenta peri-aquedutal), que é um dos componentes fundamentais nas respostas regulatórias do corpo, enviando vias eferentes, vamos encontrar o núcleo ceruleus, que se relaciona com o sistema noradrenérgico, o núcleo da Raphe, que se relaciona com o sistema serotoninérgico, a formação pontomesencefálica reticular, relacionada com o sistema colinérgico, a área ventral tegmentar, relacionada com o sistema dopaminérgico, e, mais adiante, no mesencéfalo do mesmo sistema dopaminérgico, a substância nigra.

Esses núcleos, estimulados pelos afetos, acionam os diversos sistemas que vão agir nas estruturas cerebrais por meio de substâncias neuroquímicas, neurotransmissores e peptídeos, determinando suas ações específicas requeridas em cada situação para a regulação orgânica. Assim, outras áreas são acionadas pelos estímulos vindos do corpo, como o tálamo, o hipotálamo, a amígdala, núcleos basais do cérebro anterior e o cingulado anterior. $O$ hipotálamo ocupa uma posição central na regulação orgânica pela sua importância no sistema endocrinológico. As atividades desses núcleos, com seus produtos neuroquímicos, corresponderiam aos correlatos neurais dos processos quantitativos de Freud, ou seja, ao drive ou pulsão, na acepção acima referida.

Por outro lado, por meio dos órgãos sensoriais, o mundo externo é capturado sob a forma de sensaçôes, que são enviadas para as diferentes regiōes cerebrais sensoriais unimodais e, destas, para as regiôes cerebrais unimodais secundárias, onde os dados são integrados, elaborados e memorizados, ficando disponíveis à consciência.

$\mathrm{O}$ encontro entre os dados que provêm do meio interno e os dados que se originam do meio externo se dá no lobo frontal, resultando em uma reação imediata, estereotipada, pré-programada, determinada pelo princípio do prazer. $\mathrm{Ou}$ seja, no momento em que os impulsos de busca, motivados pelas necessidades que 
deixam o organismo num estado de desprazer, de compulsividade, de premência, encontram o objeto que as satisfaça, aciona-se um padrão de descarga motora que se manifesta internamente no corpo do próprio ser, em termos secretores e vasomotores.

Freud acreditava, como sugere em Inibiçôes, sintomas e angústia (1926), que os padrōes fixos de descarga afetiva motora eram, em sua maior parte, programados de forma inata, apesar de algumas emoçôes básicas serem forjadas aparentemente durante o desenvolvimento precoce por eventos biológicos ocorridos em momentos significativos e particulares da luta pela sobrevivência, situações em que os afetos e as respostas orgânicas de descargas motoras ficam registradas como uma totalidade indissociável. A partir dessa circunstância, cada emoção adquire um caráter específico e todo afeto é reminiscência de uma experiência.

A esse respeito, escreve Freud:

Se formos adiante e indagarmos da origem dessa ansiedade - e dos afetos em geral - estaremos deixando o domínio da psicologia pura e penetrando na fronteira da fisiologia. Os estados afetivos têm-se incorporado na mente como precipitados de experiências traumáticas primevas, e, quando ocorre uma situação semelhante, são revividos como símbolos mnêmicos. Não penso haver laborado em erro ao aproximá-los do ataque histérico mais recente e individualmente adquirido, e em considerá-los como seus protótipos normais.

Isto não implica que a ansiedade ocupa uma posição excepcional entre os estados afetivos. Na minha opinião, os outros afetos são também reproduções de experiências muito antigas, talvez mesmo pré-individuais, de importância vital; e devo estar inclinado a considerá-las como ataques histéricos universais, típicos e inatos, comparados com os ataques recentes e individualmente adquiridos que ocorrem em neuroses histéricas e cuja origem e significado como símbolos mnêmicos foram revelados pela análise. Seria muito conveniente, como é natural, sermos capazes de demonstrar a verdade desse ponto de vista em um grande número desses afetos - uma coisa que ainda está muito longe de ser o caso (Freud, 1926: 140).

No meu ponto de vista, a partir de minhas observaçóes em situaçóes clínicas com adultos e com crianças em momentos precoces, essa forma de funcionamento que Freud denominou de processo primário, em que o organismo está entretido em suas limitações de recursos em face de sua imaturidade, o que o remete a uma condição de total dependência e ausência de autonomia, o mecanismo de sobrevivência é totalmente centrado na restauração do equilíbrio homeostático (do meio interno). Assim sendo, a oscilação entre o acúmulo de carga energética, que 
provoca o desprazer, e a descarga desse excesso de energia acumulada em face das demandas da necessidade e do sofrimento é o mecanismo dominante, com a utilização tão-somente das estruturas internas do corpo, vasomotoras e viscerais. Essas experiências em diversas situações é que serão inscritas como memórias, como traços mnêmicos, como já enfatizado no Projeto (1895), e que eu chamo de registros básicos de memória, que serão os parâmetros pessoais para as formas de funcionamento afetivo-emocional do indivíduo adulto.

Nesses termos, cabe minha hipótese, que sempre foi muito contestada, de que a descarga motora interna, que ocorre como ação do processo primário, baseada no princípio do prazer, constituiria o protótipo das reações emocionais futuras nas suas diversas modalidades de expressão. Ou, dizendo de outra forma, o processo primário se caracteriza pela manifestação quantitativa como expressão da carga e descarga de energia e pela expressão qualitativa restrita à dualidade simples desprazer-prazer, uma expressão afetivo-emocional grosseira, de modalidade binária, de um ego puramente corporal, como caracterizou Freud.

A discriminação mais fina entre as modalidades de afetos e emoçôes vai ocorrer num ego mais amadurecido e desenvolvido. Essa forma de descarga voltada para a modificação do próprio corpo tem secundariamente o objetivo importante de comunicar o estado de necessidade para a mãe ou cuidador. Constitui o núcleo dos mecanismos de transferência e de identificação projetiva, tão bem conhecidos na psicanálise. Esses estados correspondem aos estados da posição esquizoparanóide de Melanie Klein.

Se relacionarmos os afetos e emoções, de um lado, com as experiências de descarga e a correspondente experiência sensorial vivida em termos de prazer e desprazer por um ego primitivo, por outro lado, precisamos relacionar os afetos e as emoçôes com os impulsos motivacionais intrínsecos ou impulsos instintivos que têm origem nas disposiçõos inatas, herdadas filogeneticamente, como formas que deram certo e foram incorporadas pelos ancestrais, tendo ficado depositadas no $i d$, segundo Freud. Como já assinalamos, esses impulsos têm origem na intimidade do corpo e mobilizam o organismo em direção à sobrevivência, proporcionando experiências qualitativas sob a forma de afetos e emoções, que são chamados de básicos porque nascem com o próprio ser.

Aí temos, determinando emoções básicas positivas, segundo Jaak Panksepp (1996), os impulsos motivacionais conhecidos como seeking system ou sistema de busca, que coincide com o sistema dopaminérgico, principalmente no seu ramo mesolímbico-mesocortical, mobilizado, portanto, pelo neurotransmissor dopamina. Esse sistema leva o animal a uma atividade exploratória do meio externo, de 
busca inespecífica, mas dentro de uma condição de expectativa de se deparar com algo que corresponda à satisfação de sua necessidade, desejo ou curiosidade. Dessa forma, é uma atividade que antecipa o prazer do encontro. É por meio desse impulso que o animal, o homem inclusive, sai do estado de isolamento em si mesmo para a busca de contato com o externo, com o outro, com o que existe fora de si, ou seja, sai do narcisismo para a relação de objeto. É esse sistema que vai ser responsável pela busca do homem por objetos que satisfaçam, primariamente, a suas necessidades, e, secundariamente, a seus desejos. Podemos, pois, identificar esse sistema como correspondente ao que Freud chamou de libido, sendo por meio desses impulsos que ocorrerão as catexizações dos objetos de relação. Podemos dizer que constitui a base para as relações de objeto, da forma pela qual são estudadas na psicanálise.

Relacionado a esse sistema, existe o sistema de busca de prazer por excelência, em que o encontro por vezes leva aos quadros de fixação, de adicção, envolvendo o accumbens e o núcleo basal do cérebro anterior, que é a área responsável pelas situações de recompensa, pela secreção de opióides, principalmente. Diferentemente do sistema de busca que leva o ser a uma busca ampla, de exploração curiosa do meio, este sistema tende a restringir o ser na busca restrita do prazer pela via conhecida e consagrada, como nos mostra Freud quando se refere às fixações, e também é conhecido como luxury system ou sistema de luxúria.

Ao lado dos impulsos que levam às emoções positivas de prazer, existem aqueles que levam às emoções negativas, que derivam da herança filogenética por serem favoráveis à sobrevivência. O sistema do medo é o primeiro impulso herdado pelo homem com essa finalidade. Ele já nasce com esse sistema, que aciona um cortejo de reações corporais provocadas pelo sistema de alerta, noradrenérgico, que, por sua vez, aciona o sistema cardiocirculatório, o sistema muscular, o sistema visceral, o sistema humoral para o ato reflexo da paralisia ou da luta e fuga. Como sabemos, o circuito neuronal do medo é conhecido e não nos cabe tratar dele aqui, mas envolve basicamente a amígdala, uma estrutura que já está funcionando no momento precoce da vida do homem.

O sistema de fúria é o segundo impulso motivacional herdado, que leva às emoções negativas básicas de cólera, raiva, fúria diante das frustrações, do aprisionamento e do mal-estar. Parece que a natureza dotou o organismo dessa reação violenta de explosão motora agressiva contra o meio externo como uma forma de incrementar seus recursos diante dos obstáculos e alcançar as condições que garantem a sobrevivência. Nesse caso, a reação corporal é muito semelhante à que ocorre no medo, e os circuitos neuronais presentes nesse sistema envolvem a ação da amígdala numa porção diferente da envolvida na situação de medo. 
Por fim, temos o sistema de pânico e perda, que se refere às emoções de desespero, desamparo e distress que acompanham o bebê nas situações de perda do contato materno, uma vez que o contato intersubjetivo com a mãe, numa continuidade da vida intra-uterina por um longo período logo depois do nascimento, em que impera o estado de imaturidade biológica e psíquica do bebê, e, em conseqüência, um estado de total dependência para a sobrevivência, é uma condição também instintual no sentido de conter o impulso pré-programado de busca por parte do bebê e da mãe, num momento em que impera o estado de imaturidade biológica e psíquica do bebê. $\mathrm{O}$ cingulado anterior e o núcleo septal parecem estar envolvidos no sistema do pânico. Por essa razão, é fundamental a distinção entre pânico e medo, que não são discriminados nos quadros clínicos da chamada síndrome do pânico, já que a maior parte dos psiquiatras atribui ao medo e à região da amígdala a responsabilidade pelas manifestações clínicas. A abordagem psicoterapêutica e medicamentosa deve ser diferente nas situaçóes de medo e pânico.

Panksepp (1996) identifica outros sistemas de impulsos motivacionais presentes no homem, como o jogo, por exemplo, que não iremos considerar aqui. São impulsos que provocam emoçôes básicas, que mobilizam o ser no seu processo de garantir a sobrevivência biológica e que podemos identificar no corpo, por meio de um mecanismo de funcionamento biopsíquico que Freud denominou processo primário, porque comandado por um ego rudimentar, num esquema rudimentar determinado pelo princípio do prazer.

Podemos pensar que os sentimentos de medo, raiva, curiosidade, expectativa, pânico e desespero são interpretações que nós, adultos, atribuímos às reações do bebê, que, com isso, vai aprendendo a distinguir, a nomear, a associar significados às experiências, depois símbolos e palavras. Para o bebê, no início, na vigência do princípio do prazer, as vivências são tão-só de desprazer e prazer, de forma global, sem discriminação de qualquer outra qualidade, pois os fenômenos são predominantemente fisiológicos, envolvendo quantidades de energia, e funcionam na dualidade carga-descarga, o que levou Freud a utilizar o modelo hidráulico. Carga e descarga são captadas sensorialmente como desprazer e prazer e vão estimular as mobilizações motivacionais para alterar a condição, de forma premente, imediata e automática.

As diversas modalidades de afetos que vão sendo vivenciadas pelo bebê nascem da aprendizagem que ocorre no contato íntimo mãe-bebê, pela comunicação que se estabelece entre ambas as partes, em que a mãe, por nomeações ou por atitudes, vai transmitindo a discriminação das vivências afetivo-emocionais. A partir desse momento, afetos e emoçôes deixam de ser apenas de prazer e desprazer 
para ganhar significações e interpretações diversas e múltiplas. Paralelamente a esse processo, a mãe, com a sua postura, vai interferindo nas formas de regulação que se fazem no processo primário, apaziguando, diminuindo e, portanto, tornando mais tolerável a situação de desprazer. Com isso, a descarga vai se fazendo de forma mais atenuada e não tão premente.

Neurobiologicamente, essa comunicação se processa pelo hemisfério cerebral direito da mãe e hemisfério cerebral direito do bebê. A mãe capta, empaticamente, o que se passa com ele, entende sua vivência por meio de seus neurôniosespelho bem desenvolvidos e transmite ao bebê, de forma adequada, o que ele necessita em termos de acolhimento físico, nutricional e psíquico.

O bebê, de seu lado, com os afetos e emoções primitivos que estão operantes nesse momento no hemisfério cerebral direito (que amadurece antes do esquerdo), capta receptivamente esses estímulos que vêm da mãe, incorpora-os e registra-os sob a forma de memória, que ele vai repetir, num processo de recategorização, a cada experiência vivida como aprendizagem sobre o meio e em sua relação com ele, formando um background de conhecimento peculiar e pessoal, acumulado (memória), a partir do qual passa a se orientar referencialmente no futuro. Esses estímulos são necessários e promoverão, juntamente com a maturação determinada geneticamente, o processamento da maturação fisiológica e a aquisição de habilidades e conhecimentos, que vão permitir as mudanças no comportamento relativamente à satisfação das necessidades, ao controle dos impulsos e às formas de agir sobre o meio. Num estado de total imaturidade biológica e fisiológica, com os impulsos mobilizadores exclusivamente voltados para agir de forma automática e pré-programada sobre o meio interno, sobre o corpo, no sentido de eliminar o afeto de desprazer para alcançar o afeto do prazer, o bebê, mediante o atendimento da mãe e demais cuidadores, vai aprendendo e adquirindo as habilidades para derivar suas ações para fora de si mesmo, para o meio externo, com evidente ganho de autonomia e capacidade de movimentação.

Por força da intervenção materna, a descarga do processo primário vai sendo protelada pela atenuação do desprazer, de um lado, e pelo aumento da tolerância a ele, de outro lado. É por meio desse contato que se vai modulando a maturação das estruturas cerebrais, principalmente o córtex pré-frontal, e que se vai fortalecendo o ego, de forma que o bebê conquista a capacidade de inibir a resposta cega de descarga dos quanta de energia acumulada. $\mathrm{O}$ ego aprende a reprimir os afetos e as ações mais violentas que resultariam de sua descarga e pode "alucinar" o objeto ausente; pela utilização de situaçôes e fatos aprendidos com a mãe, inscritos em sua memória sob a forma de registros, o bebê pode acoplar símbolos e palavras à lembrança das imagens dos objetos ausentes e aos afetos e emoções, o 
que permite realizar, em nível mental e imaginário, a ação que posteriormente se exterioriza como ação externa voluntária. A ação voluntária nasce da capacidade de inibir voluntariamente a resposta que antes era automática, incontrolável, sob a forma de descarga. O ego vai adquirindo a capacidade de direcionar sua ação, de fazer escolhas e tomar decisões baseadas em experiências emocionais prévias, podendo, posteriormente, experimentar respostas novas.

Esse processo, que Freud chamou de processo secundário, em que a ação se faz no mundo externo em busca da auto-regulação orgânica por si, de forma autônoma, é regido pelo que ele chamou de princípio de realidade. A interpretação que o indivíduo faz e o significado que ele atribui ao que se passa consigo estão ampliados, não mais presos à dualidade prazer-desprazer diretamente relacionada à sobrevivência. A variação das modalidades de afetos possibilita ao indivíduo perceber uma gama de significados de seu estado, que vão afetar sua visão do mundo e o próprio significado de objetos e fatos da realidade. Os dados externos já não se restringem à relação estrita com a sobrevivência puramente biológica. $\mathrm{Na}$ medida em que os sentimentos vão se ampliando, os significados dos objetos e das situações de si mesmo e do mundo externo ampliam-se igualmente, e, por uma relação de retroação, esses significados ampliam os sentimentos vivenciados.

Esses sentimentos afetam os pensamentos e as formas de pensar, que se ampliam numa escala infinita, afetando a regulação do próprio organismo. $\mathrm{O}$ homem, no princípio fechado e restrito exclusivamente a questões, relações e ações em função de si mesmo, no estado narcísico, passa gradativamente a considerar o outro, primordialmente a mãe, na relação diádica mãe-bebê, para estender essa consideração para outras relações com outros indivíduos e com o meio externo. É a passagem do eu-ismo para o social-ismo.

Quando as áreas ventromedial do lobo pré-frontal passam a funcionar pela maturação do cérebro, como o componente cortical do sistema límbico, principalmente na sua porção orbitofrontal, o ego passa a adquirir uma capacidade de controle da auto-regulação afetiva em outro nível. Em função de experiências prévias do bebê, sob os cuidados da mãe ou de qualquer outro indivíduo que o assista, o ego torna-se capaz de inibir voluntariamente a resposta de descarga imediata, característica do processo primário. Nesse espaço, emerge a possibilidade de selecionar a resposta a ser dada pela entrada em funcionamento dos núcleos da região mediana no pré-frontal, com base em memórias de experiências emocionais prévias em situações semelhantes, já que objetos e situações do passado podem ser trazidos como imagens, num mecanismo semelhante à alucinação. Com a entrada em funcionamento da região dorsolateral do lobo pré-frontal, tornamse acessíveis ao ego os símbolos e as palavras trazidas pela mãe em suas experiências 
de nomeação, ao assistir o bebê, que se acoplam às imagens, aos objetos e às situaçôes e se tornam disponíveis à manipulação da mente como pensamentos, numa atividade de pensar, optar, decidir, agir ou conter.

O que, sob o princípio do prazer, no processo primário, era uma ação interior de descarga, sob o princípio da realidade, no processo secundário, passa a ser uma ação dirigida, voluntária, orientada para o externo, visando a modificação da situação, num processo que é mediatizado pelas funções das regiões motoras frontais. A energia que advinha dos impulsos motivacionais produzidos no interior do corpo, e que era descarregada livre e cegamente, agora se encontra acoplada, ligada às palavras e aos pensamentos, de tal forma que é descarregada sob o controle da vontade, depois de passar pelo crivo da opção. Essa é a grande transformação que ocorre quando os afetos e as emoções que estavam nos domínios das estruturas subcorticais alcançam a corticalidade sob a forma de sentimentos, que se acoplam com a consciência e com os pensamentos. São os domínios das chamadas funções executivas do lobo pré-frontal, estudadas pela neurociência, que correspondem às funções desse ego desenvolvido, que funciona no processo secundário e sob o princípio da realidade.

A partir desse momento, realiza-se o essencialmente humano, que é a extraordinária capacidade que o homem tem de desenvolver-se psiquicamente. $\mathrm{O}$ homem, na culminância de seu desenvolvimento, é capaz de transcender o significado da sobrevivência restrito ao parâmetro biológico de vida e morte, para assumir valores ético-morais por meio dos quais as conquistas da dignidade e da honra passam a ser mais preciosas do que a própria vida, e por meio dos quais o amor ao próximo, à coletividade e à natureza é mais precioso do que a própria integridade.

São as potencialidades previstas por Freud quando, em seus amargos dias, padecendo de uma dor avassaladora provocada por um câncer da mandíbula, não esmorecia na busca de seus ideais de dotar a psicanálise de recursos para desbravar os horizontes humanos sem fim, e, como nos revela a neurociência, desvelar alguns dos segredos escondidos no infinito desconhecido que é o cérebro humano.

As formas de funcionamento regidas pelo princípio do prazer permanecem presentes como forma orgânica primária, mesmo que formas de funcionamento baseadas no princípio da realidade tenham sido conquistadas. $\mathrm{O}$ atendimento às solicitações dos instintos que se faz sob a forma de descarga é domado, sua força é atenuada, e essa energia é desviada para outras formas de ação, orientadas por valores que não os estritamente relacionados ao prazer orgânico primário. São as ações que demonstram a transcendência dos valores para além do biologicamente determinado, alcançando os níveis do sublime e do sagrado. 
É importante que se diga que as formas de funcionamento baseadas no princípio do prazer permanecem porque são fundamentais para a sobrevivência, de modo semelhante ao que acontece nos sonhos. Quando o homem adormece, as estruturas neurais responsáveis pelo funcionamento sob o princípio da realidade são inibidas, assim como as atividades motoras responsáveis pela ação. Nessas circunstâncias, o homem pode descarregar as energias que se acumulam por força da frustração das necessidades e dos desejos, imposta pela instância mais desenvolvida funcionando no processo secundário, e diante da realidade que impõe limitações. O homem realiza em sonhos o que não pode realizar no mundo real com o qual se defronta quando acordado. Ele tem a possibilidade de realizar o desejo impossível e alcançar a satisfação pelo sonho.

A primazia do princípio do prazer também se encontra nas formas de funcionamento de pacientes que nos procuram em busca de ajuda para aliviar-se do sofrimento psíquico. De forma geral, essas pessoas padecem de um estado biopsíquico caracterizado pela permanência em formas de funcionamento do processo primário, baseadas no princípio do prazer, e buscam desesperadamente livrar-se do desprazer para restaurar o estado de prazer. Elas se comportam como se acreditassem que a natureza lhes prometeu um estado de prazer infindo, o nirvana; não se conformando com os momentos de desprazer, não podem aprender que esses momentos são naturais para quem está inserido na realidade da vida. Muitos desses pacientes estão aprisionados num momento precoce de seu desenvolvimento, ou devido a situações traumáticas, ou por não terem tido atendimento adequado de suas necessidades por quem os assistiu, e cristalizam a postura de quem espera que o alívio e os recursos para que eles não mais vivam situaçôes de desprazer (dor, sofrimento) venham do outro, no caso, da situação psicanalítica, do psicanalista. Nessas situações, cabe ao analista a árdua tarefa de ensiná-los a perceber e a compreender sua condição e a realidade da vida e de ajudá-los a conquistar os recursos para lidar com o desprazer, o que envolve tolerância e esforço contínuo e exige a compreensão de que o desprazer, assim como o prazer, faz parte da vida e nunca poderá ser eliminado.

\section{REFERÊNCIAS BIBLIOGRÁFICAS}

Albright, T. D.; Kandel, E. (2001). Neural science: a century of progress and mysteries that remains. Neuron, Oxford: Elsevier, v. 25, Millennial Review Suplement.

Corrigall, J.; Wilkinson, H. (2003). Revolutionary connections - psychotherapy and neuroscience. London: Karnac Books. 
Damásio, A. R. (1994). Descartes's error. New York: Grosset-Putnam.

. (1999). The feelings of what happens: body and emotion in the making of consciousness. New York: Harcourt Brace.

- (2001). Emotion and the human brain. Em Harrington, A.; Kagan, J. (Orgs.). Unity of knowledge - the convergence of natural and human science. New York: New York Academy of Sciences.

. (2003). Looking for Spinoza. New York: Harcourt.

Damásio, A. (2004). Em busca de Espinosa: prazer e dor na ciência dos sentimentos. São Paulo: Companhia das Letras.

Freud, S. (1895). Projeto para uma psicologia científica. Edição standard brasileira das obras psicológicas completas de Sigmund Freud, v. 1. Rio de Janeiro: Imago Editora, 1976.

- (1900). Interpretação dos sonhos. Edição standard brasileira das obras psicológicas completas de Sigmund Freud, v. 5. Rio de Janeiro: Imago Editora, 1976.

. (1911). Formulação sobre os dois princípios do funcionamento mental. Edição standard brasileira das obras psicológicas completas de Sigmund Freud, v. 12. Rio de Janeiro: Imago Editora, 1976.

- (1915). Instintos e suas vicissitudes. Edição standard brasileira das obras psicológicas completas de Sigmund Freud, v. 14. Rio de Janeiro: Imago Editora, 1976.

- (1920). Além do princípio do prazer. Edição standard brasileira das obras psicológicas completas de Sigmund Freud, v. 18. Rio de Janeiro: Imago Editora, 1976.

- (1926). Inibição, sintomas e angústia. Edição standard brasileira das obras psicológicas completas de Sigmund Freud, v. 20. Rio de Janeiro: Imago Editora, 1976.

Fonagy, P. (2001). Attachment theory and psychoanalysis. New York: Other Press.

LeDoux, J. (1998). O cérebro emocional (2a ed.). Rio de Janeiro: Objetiva.

Moss, H.; Damásio, A. R. (2001). Emotion, cognition and the human brain. Em Harrington, A.; Kagan, J. (Orgs.). Unity of knowledge - the convergence of natural and human science (pp. 98-100). New York: New York Academy of Sciences.

Panksepp, J. (1996). Affective neuroscience - the foundations of human and animal emotions. Oxford: OUP.

Schore, A. N. (1964). Affect regulation and the origin of the self. New Jersey: Lawrence Erlbaum.

(2003). Affect regulation and the repair of the self. New York: W. W. Norton.

Soussumi, Y. (1994). A psicanálise de hoje é freudiana? A psicanálise e algumas idéias neurobiológicas e imunoendocrinológicas. Em Junqueira Filho, L. C. U. (Org.). Corpo mente - uma fronteira móvel (pp. 351-391). São Paulo: Casa do Psicólogo.

. (2003). Uma experiência prática de psicanálise fundamentada pela neuropsicanálise. Revista Brasileira de Psicanálise, 37, 2/3, 573-596. São Paulo: Associação Brasileira de Psicanálise. 
- (2005). Afetos, sobrevivência e desenvolvimento na neuro-psicanálise. Revista Brasileira de Psicanálise, 39, 3, 129-134. São Paulo: Associação Brasileira de Psicanálise. Watts, D. F. (2003). Psychoterapy in an age of neuroscience: bridges to affective neuroscience. Em Corrigall, J. \& Wilkinson, H. Revolutionary connections (pp. 79117). London: Karnac Books.

Wilson, E. O. (1998). Consiliense: the unity of knowledge. New York: Knopf.

Recebido em 16 de fevereiro de 2006 Aceito para publicação em 20 de março de 2006 